\section{Biologists become clock-watchers}

\author{
Chronobiology: Biological \\ Timekeeping \\ edited by Jay C. Dunlap, Jennifer J. Loros \\ \& Patricia J. DeCoursey \\ Sinauer: 2003. 382 pp. $\$ 74.95$ \\ Palgrave: 2003. $£ 47.99$
}

\section{John Palmer}

It is well known that the lives of most plants and animals are tuned to the night-day cycle. Most birds are active during the day, most bats at night. Many flowers open during the day and close their petals at night. Except for insomniacs and shift-workers, humans sleep at night. For centuries the axiomatic interpretation was that these alternating with nights. But halfway through the twentieth century this interpretation ered then that within the bodies of virtually all organisms is a living clock that governs their periodic behaviour. The discipline of chronobiology has since been created to study this innate periodicity, the ultimate goal being to decipher the clockwork.

Chronobiology was written to support a course on this subject for advanced undergraduates and graduate students in the life sciences. At

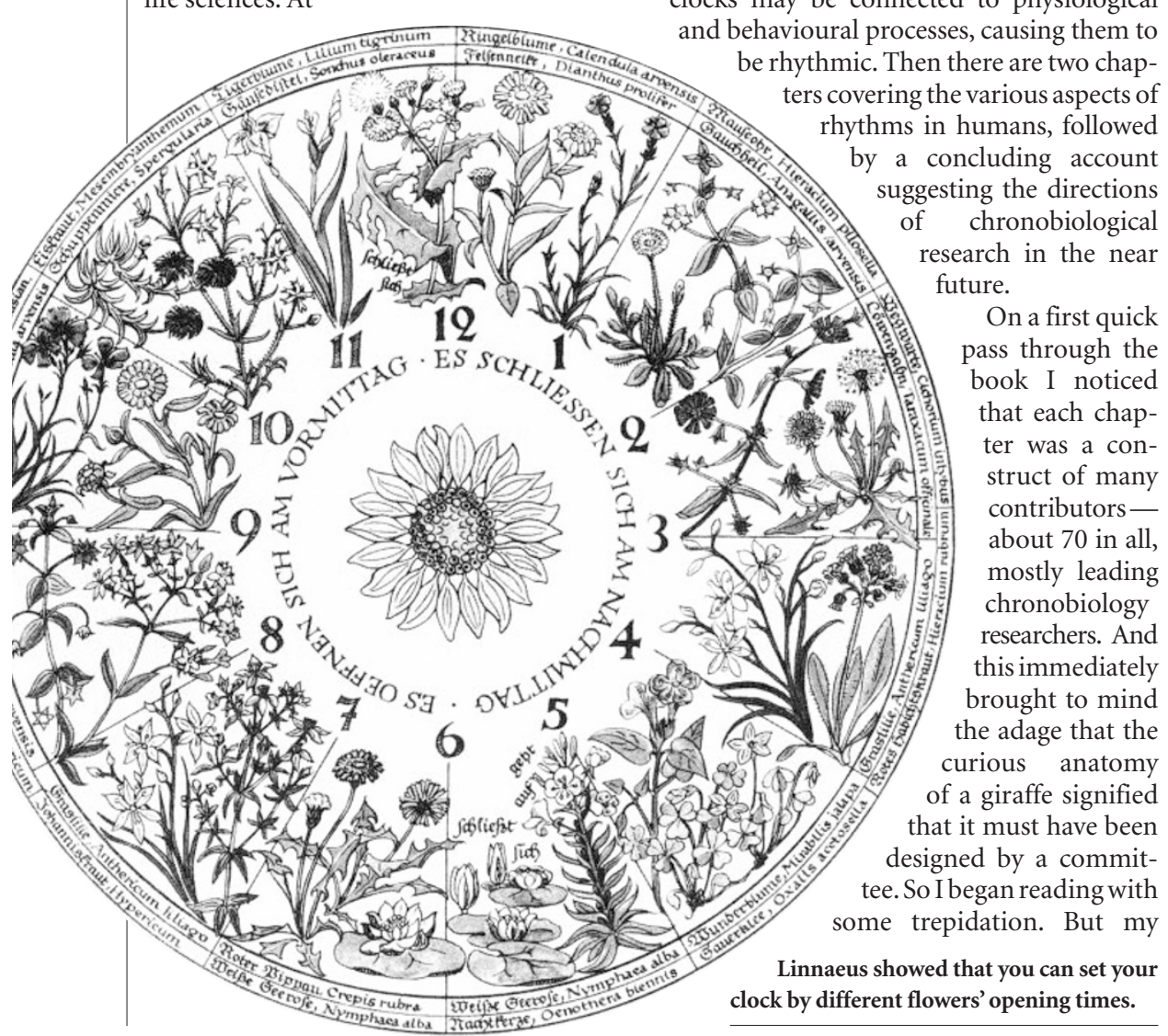
such a course. Its opening chapter provides an overview of the field, but I feel that many readers will have problems in understanding it. It presents too much, too briefly (in just 12 pages), before uninitiated readers have even been given a feeling for what biological rhythms are. That could be a turn-off to some.

The information presented in the second chapter might have made a better introduction. It introduces the reader to the most commonly studied clock-controlled rhythms in the plant and animal kingdoms, emphasizing those based on the 24-hour length of a day. It then describes the clock's use in Sun-compass orientation (it corrects for the changing position of the Sun as it crosses the sky), seasonality and time sense. The examples are well-chosen and informative. The book then goes on to describe how rhythms are entrained to environmental cycles, and discusses the innate nature of the clock and the clockwork's general rate-insensitivity to different constant temperatures.

Next up is a section about the genetics of the clock (the frq gene in the fungus Neurospora, and the per gene in the fruitfly Drosophila) and the location of the clock in various organisms (the brain in certain insects, the eye in some molluscs, and the eye, pineal gland and part of the brain known as the suprachiasmatic nuclei in vertebrates). There is a discussion about how these clocks may be connected to physiological and behavioural processes, causing them to hythmic. Then there are two chapchythm in humans, followed y a concluding account of esearch in the near ass through the book I noticed ach chapabout 70 in all, mostly leading chronobiology researchers. And this immediately brought to mind the adage that the curious anatomy of a giraffe signified that it must have been tee. So I began reading with some trepidation. But my activities were directly governed by days was found to be inadequate; it was discov-

present, no other book is well suited for concern was for nought. The presentation reads smoothly (although it is wordy and too academic in places) and is well-organized about half of it was written and overseen by one of the editors. All of the topics that must be covered in a text on chronobiology are present. And the production of the book is superb: the many illustrations and photographs are beautifully reproduced and the layout is uncluttered and appealing, so students should like it.

In a nutshell, I take my hat off to the many contributors and the publisher for their efforts. The stated goal of the preface has been accomplished - the field now has its much-needed textbook.

John D. Palmer is in the Department of Biology, University of Massachusetts, Amherst,

Massachusetts 01003, USA.

\section{A dangerous world?}

The Suffering Gene: Environmental Threats to our Health

by Roy Burdon

Zed Books: 2003. 227 pp. \$59.95, £45 (hbk); \$19.95, £12.99 (pbk)

\section{Roger Cox}

In The Suffering Gene, Roy Burdon explores areas of environmental concern in which science, special interests, public opinion and regulatory requirements are frequently uncomfortable bedfellows. He addresses the extent to which environmental factors, particularly those associated with industrial activities and new technologies, can affect human health. The book also touches on the difficulties of establishing an acceptable balance between the socio-economic benefits of certain human activities and the associated risks to health.

Burdon sets about his task with obvious enthusiasm. He commences with outlines of DNA structure, function and response to damage, and subsequently covers the known or suspected health effects of different types of radiation, chemical agents and free radicals. The biological mechanisms that operate to defend against these health effects (such as DNA repair and apoptosis) also receive attention. The main emphasis of the early chapters is the risk of cancer, including heritable susceptibility, but germline mutations, developmental abnormalities and ageing are also addressed.

Later chapters cover methodologies and concerns relating to recombinant organisms and human cloning. Burdon also includes discussion of the possible consequences of global climate change and, at various points in the book, touches on topics that are somewhat peripheral to the main environmental theme, such as cancer therapy and gene therapy to treat inherited diseases. 
All of these topics are dealt with in 227 pages, so this is not a book for specialist readers - many of whom will find, as I did, some deficiencies in the scientific discussions and a few errors of fact or interpretation. However, this broad coverage, together with Burdon's ability to write in a straightforward and engaging manner, should ensure that a lay audience will find it a useful scientific introduction to the effects of the environment on health.

For this target audience, a significant strength of the book is its generally balanced discussion of the health risks posed by environmental agents. For example, although Burdon emphasizes concerns about the potential risk of cancer from environmental radiation and chemicals, this is balanced by a discussion of the endogenous risk from chemical radical attack on DNA during normal cellular metabolism. Are there significant omissions or ambiguities in the book? I will address two that I thought to be important.

First, given that risks of cancer from genotoxic environmental agents generally involve low levels of exposure, I was surprised to find so little discussion of a long-standing debate concerning dose and response. There is a school of thought (E. J. Calabrese and L. A. Baldwin Nature 421, 691-692; 2003) that, at these low doses, there is an initial dose interval where cancer risk may be discounted (a threshold for risk) or where there may even be health benefits for the exposed individual (hormesis). In general, these proposals have not been viewed favourably by the national and international scientific bodies that consider risks from physical and chemical genotoxic agents. A discussion of the scientific components of the debate would have been most valuable.

My second point concerns one of the central arguments on the contribution of environmental factors to human cancer risk. Burdon emphasizes proposals that environmental factors can account for $80-90 \%$ of human cancers, and that the increasing cancer burden in the population "parallels the gradual industrialisation of the world and the widespread introduction of new synthetic chemicals into the workplace". Although he refers to difficulties in quantifying the potential impact of environmental carcinogens and the importance of other environmental influences such as diet, I sense a degree of ambiguity in his approach. Consequently, lay readers could be forgiven for interpreting some parts of the text as reflecting scientific support for the view that involuntary exposure to environmental carcinogens is a major determining factor in human cancer risk. In my opinion, it is unlikely to be so.

In particular, although there is qualified acceptance of the view that heritable factors may account for $10-20 \%$ of cancer in Western populations, this does not imply that the remaining $80-90 \%$ of cases can be attributed

\section{Exhibition \\ Unnatural causes}

Successive technological revolutions have had an impact on both the natural world and society, radically changing their relationship. The Tenth International Biennale of Photography, entitled In Nature and showing in Turin, Italy, until 12 October, reflects the individual relationships of more than 30 artists with nature in an era of scientific dominance.

Death is a frequent theme in this powerful exhibition. For example, British documentary photographer Clive Landon recorded the horror of the livestock slaughter and burning during the 2001 outbreak of foot-and-mouth disease. One of his photographs recalls the pastoral ideal of a John Constable painting - but a closer look reveals that all the cows are dead.

Kiev artist llya Chichkan responds to the darkness of modern Ukrainian history. Ten years ago he 'borrowed' the deformed fetuses from mothers living in Kiev during and after the Chernobyl nuclear accident. The fetuses were preserved in formalin at the University of Kiev's medical school. Chichkan dressed them in jewels, like the sleeping princes of Ukrainian legend, and photographed them, as shown here, in the serene poses of a normal sleeping child, imposing an anachronistic dignity.

Alison Abbott

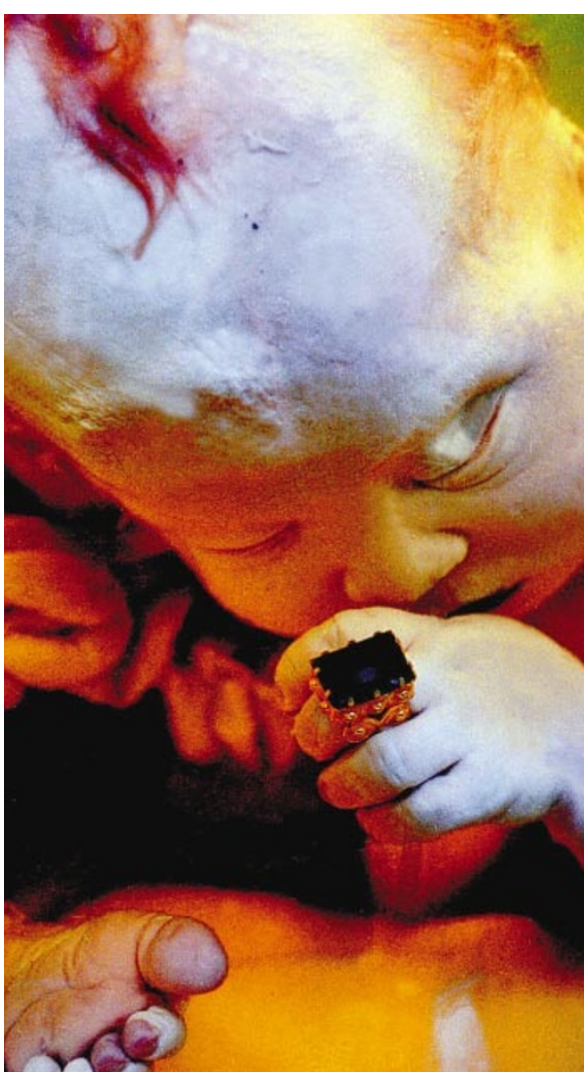

to environmental carcinogens. Although exposure to carcinogens, especially tobacco smoke, is certainly important, the nongenetic component of cancer incidence in a given population incorporates a broad range of interacting elements that may be expected to vary over time with social and economic change. These include population structure and lifestyle-related factors such as diet, reproduction and certain forms of infection (R. N. Hoover N. Engl. J. Med. 343, 135-136; 2000 and www.iarc.fr/WCR).
Given their importance to a major theme of the book, these issues could have been discussed with greater clarity.

Overall, however, I found The Suffering Gene to be a readable and reasonably balanced introduction to DNA-related environmental issues. The discussion is a little speculative or lacking in depth in places, but given the range of issues considered, this is probably inevitable.

Roger Cox is at the National Radiological

Protection Board, Chilton, Didcot OX11 ORQ, UK.

\section{Reissued classics}

The Life of Erasmus Darwin

by Charles Darwin (edited by Desmond King-Hele)

Cambridge University Press, £17.50

First unabridged edition.

Feynman Lectures on Gravitation

by Richard P. Feynman, Fernando B. Moringo

\& William G. Wagner

Westview, £24.99

Philosophers at War: The Quarrel Between Newton and Leibniz

by A. Rupert Hall

Cambridge University Press, £22.95
Gehennical Fire: The Lives of George Starkey, an American Alchemist in the Scientific Revolution

by William R. Newman

University of Chicago Press, \$27.50, £19.50

"Newman shows us how studying an obscure and ambiguous figure can bring the science of a period to life." David Knight Nature 373, 669 (1995).

The Making of Memory: From Molecules to Mind

by Steven Rose

Vintage, £8.99

A revised edition. 